\title{
2000 - A pivotal year for the CTS
}

\author{
Louis-Philippe Boulet MD, President, Canadian Thoracic Society
}

$\mathrm{T}$ he year 2000 is becoming a pivotal one for the Canadian Thoracic Society (CTS), not only because of the joint annual meeting with the American Thoracic Society for the first time in many years or the beginning of new Canadian Institutes for Health Research (CIHR) activities, but also because of many other initiatives. I will briefly review some of those activities in the next few paragraphs.

First, a word on the CIHR. The Governing Council of the CIHR recently released a list of the names of the new institutes (for a complete list, please visit the CIHR web site at www.cihr.ca). The mandate of each institute is to be determined and an action plan should be submitted in the next few weeks. As we suspected, the cardiovascular and respiratory communities have been partnered in the Circulatory and Respiratory Health Institute. We should be quite active in trying to maintain a 'respiratory' identity in this large group, and $\mathrm{Dr}$ Malcolm King will lead the group in this task.

In regard to research, meetings will take place this fall to establish a new Clinical Trials Group. This will reflect the CIHR goals and should allow for increasing collaboration among Canadian researchers. However, the specifics about such a group need to be discussed further and an agenda for the next year planned.

Revision of Canadian standards on disease management is one of the CTS members' tasks. The Recommendations on Tuberculosis have been thoroughly reviewed by the group led by Dr Richard Long. This exhaustive document has been enriched by new additions such as recommendations on pediatric care for tuberculosis. The standards on alpha-1 antitrypsin replacement therapy have also been reviewed, and we foresee the revision of other such documents in the near future thanks to the good work of the Standards Committee as well as the disease-specific committees.

On another note, the patient's version of the Canadian Asthma Consensus Guidelines should be available soon. Recent Canadian studies revealed that asthma is far from being well con-

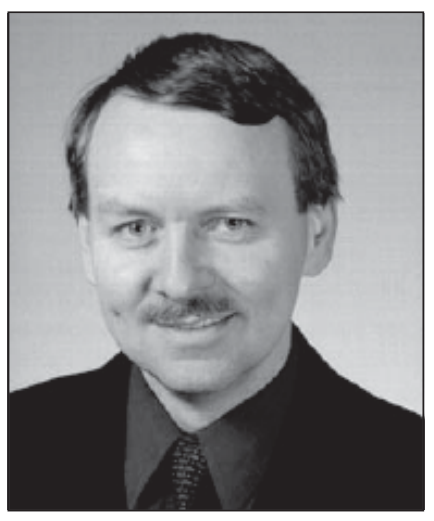
trolled in many Canadians, and that they often do not know what they can achieve in regard to optimal control, following education, adequate preventative measures and pharmacotherapy. Too many Canadians tolerate troublesome symptoms and should be informed about when to consult or modify their treatment. Hopefully, such a document will help asthma sufferers seek care when needed and reduce the burden of this disease.

Finally, proposals to develop a CTS Pulmonary Vascular Disease Committee have been received. This committee would provide an interesting opportunity to develop links with the cardiovascular group of the Circulatory and Respiratory Health Institute. Further discussions will take place on this topic, and I would like to consider the possibility of adding other committees, such as one regarding sleep apnea.

In the meantime, I wish you a nice end of the summer and hope your holidays have been up to your expectations. 


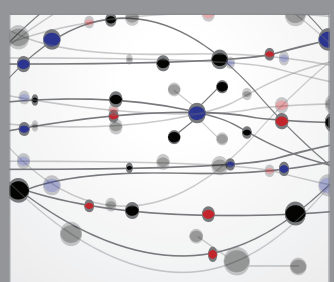

The Scientific World Journal
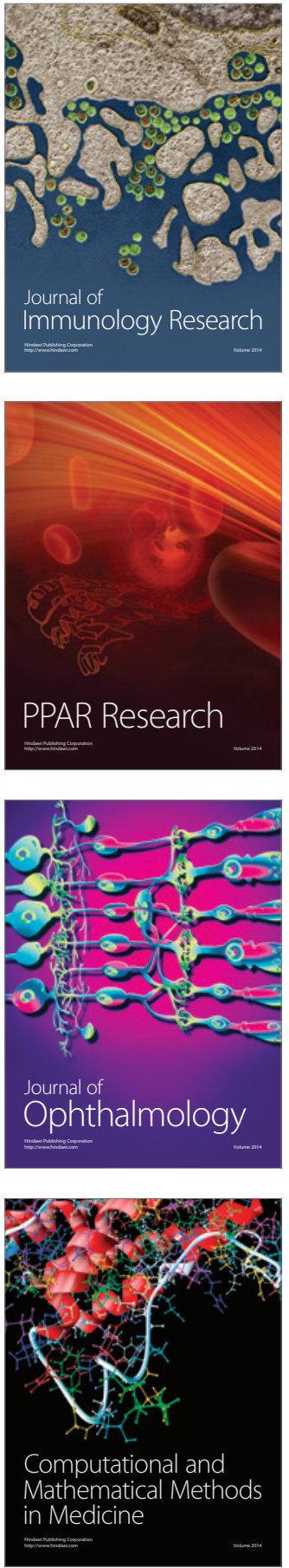

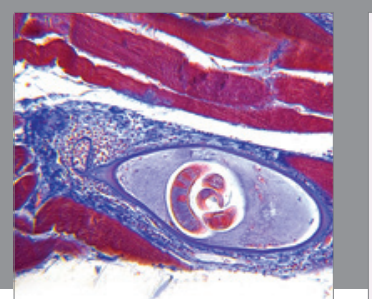

Gastroenterology Research and Practice

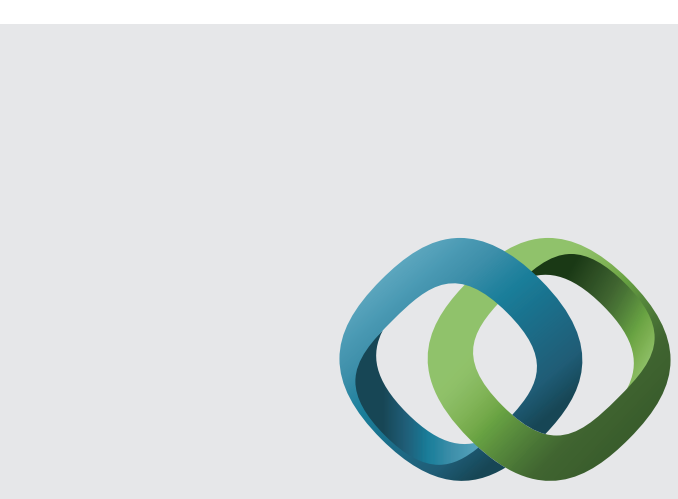

\section{Hindawi}

Submit your manuscripts at

http://www.hindawi.com
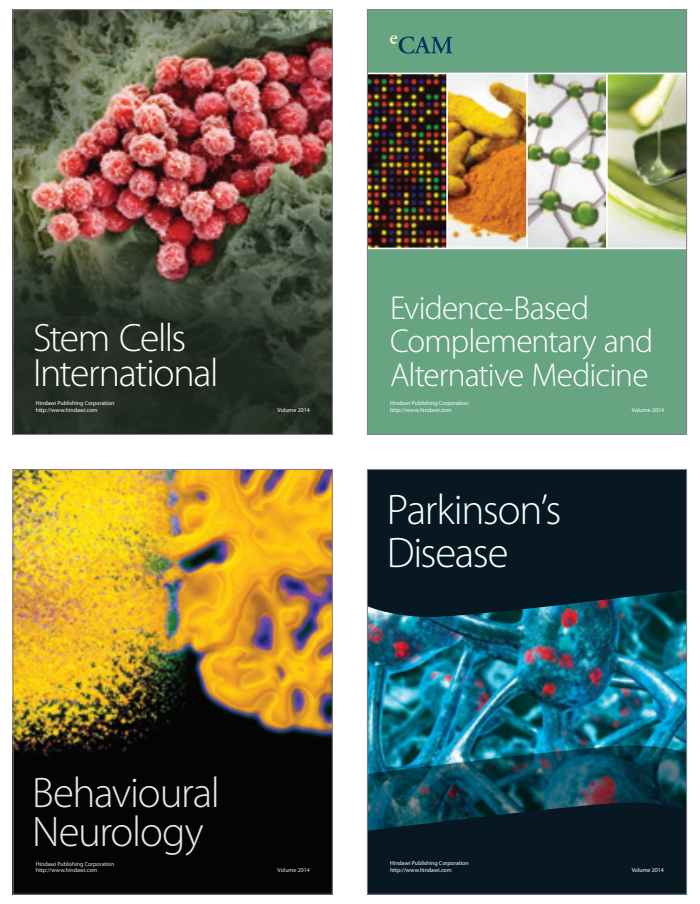
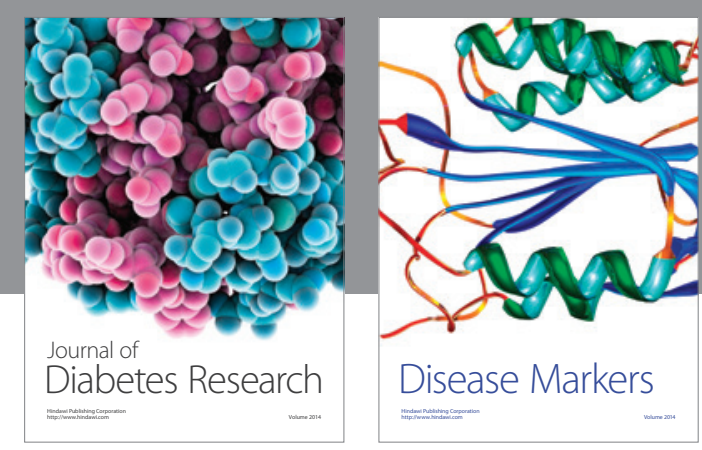

Disease Markers
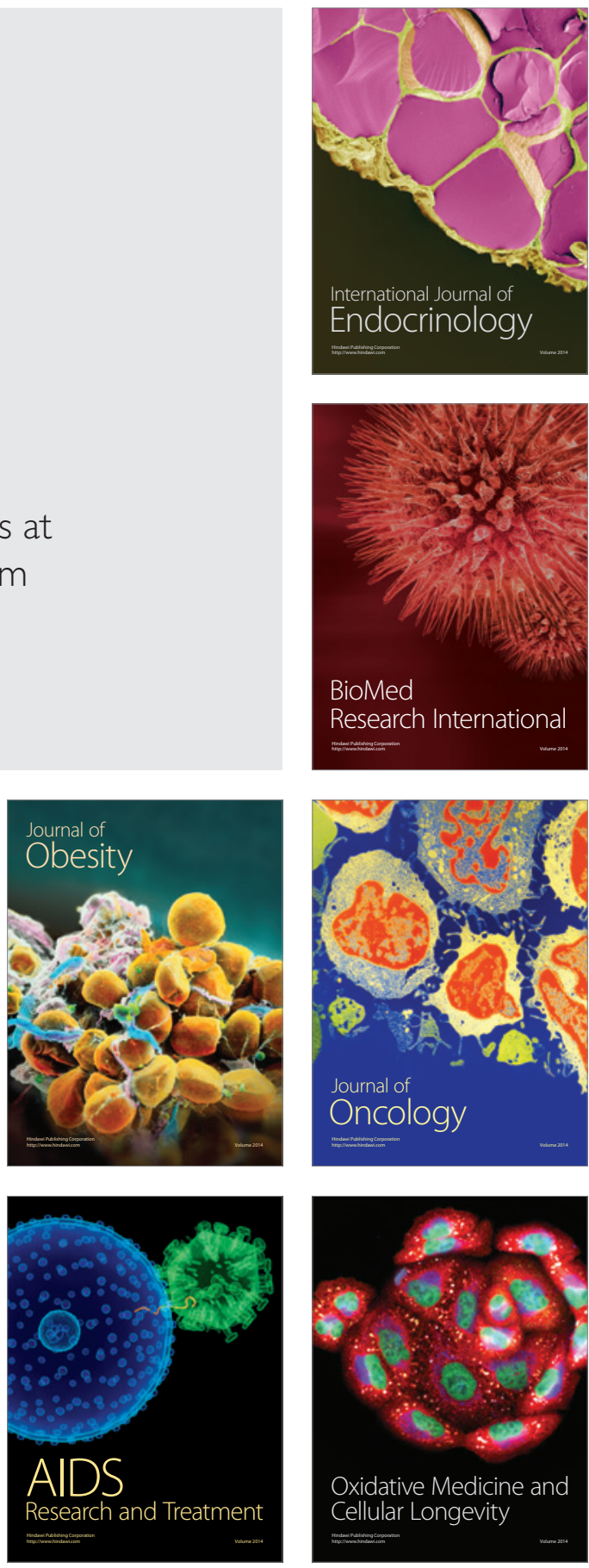